\title{
Uncertainty Analysis Applied to Supervised Control of Aphids and Brown Rust in Winter Wheat. Part 1. Quantification of Uncertainty in Cost-Benefit Calculations
}

\author{
W. A. H. Rossing \\ Department of Theoretical Production Ecology, Agricultural University, \\ PO Box 430,6700 AK Wageningen, The Netherlands
}

\author{
R. A. Daamen
}

Research Institute for Plant Protection (IPO-DLO), Wageningen, The Netherlands

$\&$

M. J. W. Jansen

Centre for Agrobiological Research (CABO-DLO), Wageningen, The Netherlands

(Received 1 October 1992; accepted 3 March 1993)

\section{ABSTRACT}

Information on the uncertainty about predicted costs and benefits of chemical control is an indispensable, but ustally ignored, aspect of decision support in crop protection. The consequences of ignoring uncertainty are illustrated using a model for evaluating financial loss associated with different strategies of chemical control of aphids (especially Sitobion avenae) and/or brown rust (Puccinia recondita) in winter wheat in The Netherlands. Crop development, population dynamics and damage are simulated as a function of predicted average daily temperature and a time sequence of decisions on chemical control. The model is intialized with temperature sum and incidences of aphids and brown rust. Uncertainty about model output is computed from uncertainty about model parameters and inputs which are quantified using field data. The probability distribution of financial loss is estimated by stratified sampling from the input distributions followed by Monte Carlo simulation. Compared to no control,

419

Agricultural Systems 0308-521X/94/\$07.00 (c) 1994 Elsevier Science Limited, England. Printed in Great Britain 
chemical control of both aphids and brown rust may reduce the range of possible financial loss. Because the probability distributions of financial loss associated with no chemical control have long right tails, uncertainty leads to damage thesholds well below the deterministic thesholds, e'ven when indifference to risk is assumed. In connurison, the damage thresholds currently used in the decision support system EPIPRE are risk-aroiding for aphids, and approximately risk-neutral for brown rust.

\section{INTRODUCTION}

In The Netherlands, the use of fungicides and insecticides became common practice in winter wheat cultivation in the 1970s when effective fungicides were registered for use (Daamen, 1990). A computer-based advisory system, called EPIPRE, was developed to supply participating farmers with fieldspecific recommendations on chemical control of discases and aphids (Zadoks et al., 1984). The recommendations are based on cost-benefit analysis of pesticide application, using quantitative models to predict aphids and disease population growth and damage. Farmers' observations of aphid and disease incidence in their ficlds are used as initial conditions (Drenth et al., 1989). Chemical control of pests and diseases based on an explicit evaluation of costs and benefits is known as supervised control (Chiarappa, 1974).

In EPIPRE, as in many other operational advisory systems (Gold, 1989), uncertainty about predicted costs and benefits of chemical control is not taken into account. In general, such simplification is allowed only when two conditions are met. The first condition is when the relations in the model are linear. In that case, the average outcome of the model under uncertainty equals its outcome without uncertainty. Although this is rare in models of biological systems, optimal decisions may be relatively insensitive to non-linearity due to the inherent robustness of binary decision variables (Thornton et al., 1984). The second condition is when the decision maker, the user of the model's output, is not interested in risk, i.e. the possibility of an unfavourable outcome of a decision. Acting upon average costs and benefits while ignoring other aspects of the probability distributions is rational only for decision makers who are neither riskaccepting nor risk-avoiding (Carlson, 1970; Sinn, 1983). In The Netherlands, the risk attitude of wheat farmers in relation to decisions on pesticide use has seldom received attention in research (Zadoks, 1989). From other countries both risk-accepting and risk-avoiding attitudes have been reported (Thornton et al., 1984; Tait, 1983; Carlson \& Main, 1976). Thus, both conditions for a priori ignoring uncertainty and risk appear not to be satisfied. 
This paper is the first of three in which we explore the uncertainty in a decision model which is used to evaluate options for chemical control of aphids (especially Sitobion arenae) and brown rust (Puccinia recondita) in winter wheat, and the consequences of uncertainty about model predictions for damage thresholds. The damage threshold (Zadoks, 1985) is defined as the level of pest attack at which the benefit of control just exceeds its cost (Mumford \& Norton, 1984). The model computes costs of time series of decisions on chemical control for specific initial conditions, comprising current temperature sum and incidences of aphids and brown rust. Costs are calculated at field level. The time scale of the model is from ear emergence to dough ripeness, i.e. approximately from early June till late July. The spatial scale is a field of winter wheat in The Netherlands of 5-10 ha. The model represents an updated and upgraded version of part of the EPIPRE system. Aphids and brown rust are considered because they often occur simultaneously. Diseases other than brown rust are left out of the analysis in view of the exploratory nature of the study.

In this paper, the uncertainty about components of the model and its consequences for model output are evaluated. In the next paper, the relative contributions of the different sources of uncertainty are assessed (Rossing et al., 1994h). In the third paper, the concept of damage threshold is reviewed in relation to uncertainty (Rossing et al., 1994a).

\section{DESCRIPTION OF THE DECISION MODEL}

\section{General structure}

The components of the decision model are shown in Fig. 1. The core of the model is a set of mathematical relations which describe the dynamics of the biological subsystems crop development, population dynamics of aphids and brown rust, and their associated damage, as a function of chemical control. The parameters in the relations are estimated using empirical data. Exogenous variables which are input to the model comprise the temperature sum calculated from the time when crop development state equalled pseudo-stem elongation (DC 30, decimal code of crop development, Zadoks et al., 1974), the future average daily temperature, and the initial aphid and brown rust incidences. The decision variables describe the nature of the intervention in the system: no chemical control or chemical control of aphids and/or brown rust. A control strategy is defined as a series of consecutive decisions on chemical control in the course of the planning horizon, i.e. the time span until crop development stage dough ripeness (DC 33). The output variable of major interest is 


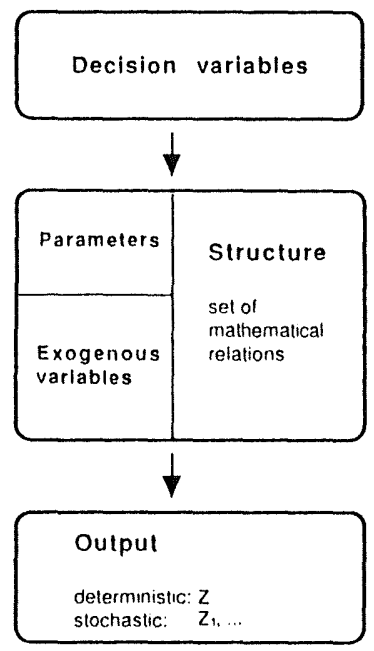

Fig. 1. Schematic representation of the components of the decision model.

financial loss. Financial loss is defined as the financial equivalent of yield reduction due to aphids and/or brown rust, plus the eventual costs of chemical control. The output is stochastic when uncertainty about the various components of the decision model is taken into account. Notation is summarized in Appendix 1.

\section{Sources of uncertainty about the model output}

Uncertainty about the predicted financial loss originates from three different sources: (1) uncertainty about the structure of the mathematical relations, caused by limited understanding of the system under consideration and by simplification of complex processes; (2) uncertainty about model parameters, due to variation in the data used to estimate the parameters; and (3) uncertainty about exogenous variables which are input to the model.

The following should be noted, relating to the above three points:

(1) In this paper, uncertainty about model structure is not taken into account. The structure of the various relations is presumed truthful as well as useful (Penning de Vries, 1977).

(2) The parameter values in the decision model are estimated from data collected in experimental and commercial wheat fields. Variation in these data is caused by variation between fields and variation within a field (Fig. 2). Variation between fields can be attributed to factors such as year, soil type and cultivar by variance-reducing 


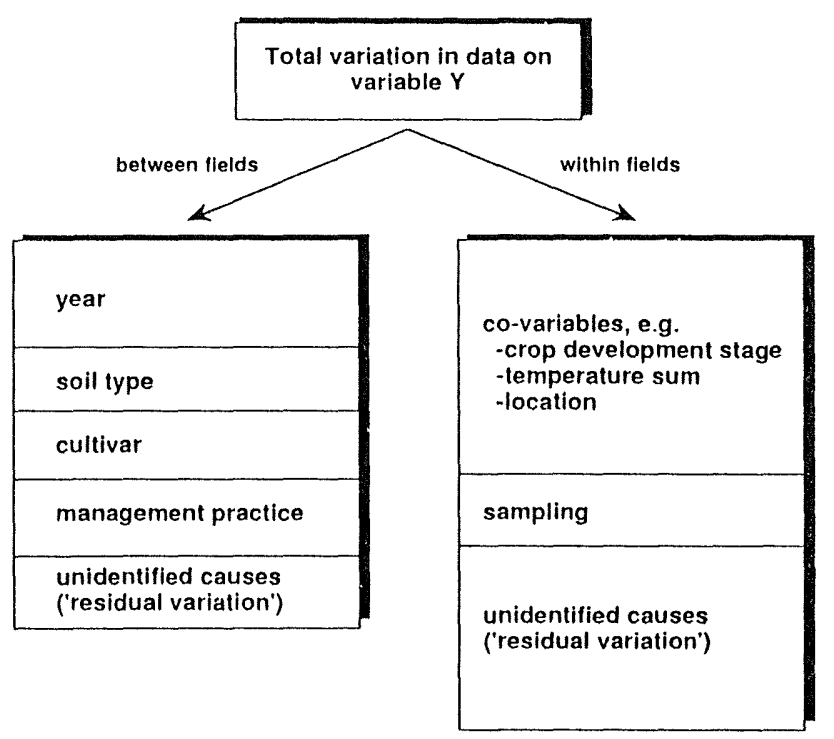

Fig. 2. Illustration of allocation of variation in empirical data of an imaginary variable $Y$ to different sources. The surface area of a rectangle represents the contribution of the respective source to total variation. The contribution is determined by analysis of variance, regression or other variance reducing techniques.

techniques such as regression. Within-field variation is caused by limited sample size in combination with spatial heterogeneity due to biological, soil and microweather characteristics. Within-field variation can be reduced by accounting for co-variables and correcting for variation due to sampling. The residual variation is commonly attributed to sampling, and can be ignored for prediction of financial loss. However, when information is available to rule out sampling as a major cause of residual variation, the variation must be regarded an inherent part of model uncertainty, caused by the simplified representation of complex ecological processes. For prediction of financial loss the random deviations of the empirical data from the fitted regression model are described as mutually independent, identically distributed normal variates or, succinctly, white noise (Feller, 1971).

(3) Uncertainty about the various exogenous variables has different causes. Uncertainty about future average daily temperature is caused by the inherently stochastic nature of temperature. This type of variation can be described by stochastic weather generators (e.g. Geng et al., 1985) or by sufficient historic data. Uncertainty about the initial temperature sum and uncertainty about the initial incidences of aphids and brown rust are caused by limited sample 
size and can be quantified with statistical methods. Inaccuracy of data due to errors in scoring samples or due to systematic errors during data collection is disregarded.

\section{Decision variables}

The decision variables concern decisions on chemical control of aphids and/or brown rust at the onset of each of $N$ decision periods. A decision period is defined as the time between two subsequent decisions. One of four decisions can be implemented in decision period $i$ : no treatment $\left(d_{i}=1\right)$, treatment of aphids $\left(d_{i}=2\right)$, treatment of brown rust $\left(d_{i}=3\right)$, and treatment of both aphids and brown rust $\left(d_{i}=4\right)$, where $i=1, \ldots, N$. Three aspects of a decision are considered: the nominal costs $C\left(d_{i}\right)$, the fraction of the target population killed on the day a decision is implemented, the direct pesticidal effect $K_{Y}\left(d_{i}\right)(X=A$ for aphids, $X=B$ for brown rust), and the period of time during which growth of the target population is arrested due to the control decision, the effective period $P_{X}\left(d_{i}\right)$. Whether population growth on day $t$ is zero is expressed by the binary function $R_{X}(t) . R_{X}$ assumes the value 1 if residual pesticidal effect is present, i.e $0 \leq t-t_{a} \leq P_{Y}\left(d_{i}\right)$, where $t_{a}$ is the day decision $d_{i}$ is implemented and $t$ is the current day. $R_{X}$ is 0 otherwise. The costs associated with a decision, $C$, consist of costs of pesticide, labour, machinery and wheel damage. The following simplifying assumptions are made: (1) decision periods are of fixed length; (2) application of pesticides is carried out on the first day of a decision period; (3) pirimicarb is used against aphids, while triadimefon, fenpropimorph or propiconazole are used to control brown rust; and (4) prices of wheat and pesticides are fixed. Estimates of $K_{X}$ and $P_{X}$ and their variation are based on information in the literature.

Future average daily temperature

Average daily temperature is calculated as the mean of daily (i.e. 24hourly) maximum and minimum temperatures. The variation in future average daily temperature is described by a sample of 36 years of daily maximum and minimum temperatures measured at the meteorological station of the Wageningen Agricultural University. This sample is considered to represent the variation in temperature in an arbitrary field of winter wheat for which predictions are made. The various yearly temperature sequences are assumed to occur with equal probability. Correlation between years is disregarded.

Crop development

Development of winter wheat from DC 30 is a function of temperature. 
At DC 30, vernalization has been completed and effects of photoperiod (see Van Keulen \& Seligman, 1987) will be negligible. Data of Carter et al. (1982) are used to regress crop development stage $D$ on temperature sum $T$. Crop development stage was monitored at least weekly in three winter wheat fields around Norwich, England, in 1977, starting on the day $50 \%$ of the tillers in a field reached DC 30. No information on sample size or cultivars was given. Temperature sum was calculated as the integral over time of the average of daily minimum and maximum temperatures, with a development threshold of $6^{\circ} \mathrm{C}$, starting on the day of the first sample. Temperature data were obtained from a nearby meteorological station. Since temperature was not measured in a field, within-field variation of temperature cannot be accounted for. The temperature sum at the start of the planning horizon, $T_{0}$, is input for the model. Variation in $T_{0}$ is assumed negligibly small.

Population growth of aphides and hrown rust

Similar models are used to describe the population growth of aphids and brown rust. Population density on day $t$ in decision period $j$ is approximated by

$$
X=\left(\prod_{i=1}^{j}\left(1-K_{X}\left(d_{i}\right)\right)\right) X_{0} \exp \left(\sum_{\tau=1}^{1}\left(1-R_{X}(\tau)\right) r_{X}(\tau)\right)
$$

where $X$ represents the aphid density $\left(A\right.$, tiller $\left.^{1}\right)$ or the brown rust sorus density $\left(B\right.$, leaf $\left.{ }^{\prime}\right)$ on day $t, X_{0}$ the initial aphid or brown rust density, and $r_{X}$ represents the relative growth rate of the aphid population $\left(r_{A}\right.$, day ') or the brown rust population $\left(r_{B}\right.$, day ') when no pesticide is applied.

Unpublished data (R. Rabbinge \& W. P. Mantel) are used to estimate the relative growth rate of unsprayed aphid populations. The data comprise weekly estimates of aphid density (mainly $S$. avenae) and crop development stage. Sample size varied between 40 and 600 tillers per field. The coefficient of variation of aphid density was at most $20 \%$. The data were collected in observational studies in fourteen commercial and experimental fields during seven years, on eight cultivars of winter wheat in The Netherlands.

Data of Daamen (1991) are used to estimate the relative growth rate of unsprayed populations of brown rust sori. The data comprise estimates of crop development stage and number of brown rust sori on fully expanded leaves, based on fortnightly samples of green leaves from 80 culms. The data were collected in eight field experiments with six cultivars between 1983 and 1986 in The Netherlands. 
Assuming the population density to change exponentially between consecutive sampling dates $\Delta t$ days apart, the relative growth rate of the population is calculated as:

$$
r_{X}=\frac{\ln (X(t+\Delta t))-\ln (X(t))}{\Delta t}
$$

Analysis of variance using multiple regression analysis with dummy variables (Chatterjee \& Price, 1974) is performed to evaluate the effect of the factors year, cultivar and crop development stage on $r_{X}$. Variation is observed crop development stage is assumed negligible.

\section{Incidence-density relations of aphids and brown rust}

The model is initialized with a sample estimate of current population intensity in a particular field. In EPIPRE, the sample is taken according to a protocol in which the incidence $I_{\lambda}$, the fraction of tillers infested with aphids, is determined in a random sample of 100 tillers, while the incidence $I_{B}$, the fraction of green leaves containing one or more brown rust sori, is determined in a random sample of 40 tillers. These incidence estimates are subject to binomial sampling error.

The incidences are converted into initial densities, $X_{0}$, using an empirical incidence-density relation (Nachman, 1981) for both aphids and brown rust:

$$
\ln \left(X_{0}\right)=\alpha_{1 . X}+\alpha_{2, X} \ln \left(\ln \left(\frac{1}{1-I_{X}}\right)\right)
$$

Data of Rabbinge et al. (1980) are used to estimate the parameters of eqn (3) for aphids while parameter estimates for brown rust are given by Daamen (1991). The data for aphids comprise weekly incidence and density estimates, both determined in the same random sample of 40 to 600 tillers per field. Sample size was adjusted to ensure the coefficient of variation to be less than $0 \cdot 2$. The data stem from observational studies in commercial and experimental winter wheat fields with various cultivars. In the data no distinction was made between fields.

The data for brown rust comprise fortnightly incidence and density estimates, both determined at the same random sample of green leaves from 80 tillers. The data stem from experiments carried out over three difference seasons, with four different cultivars. Analysis of variance was used to evaluate the effect of year, cultivar, crop development stage, and field on the relation.

Data collection for both aphids and brown rust was carried out by experienced observers and incidence and density are assumed to be 
measured without observer bias. The samples are representative for the field they originate from.

Damage due to aphids

The rate at which cereal aphids cause damage depends on the development stage of the crop and the attainable yield, i.e. the yield in absence of pests and diseases (Rossing, 1991 b). Because of lack of field data, a simulation model of post-anthesis growth of winter wheat into which effects of aphids were incorporated (Rossing, 1991a) was used to calculate the rate of daily damage accumulation per aphid as a function of crop development stage. Damage during various periods of crop development was calculated by repeatedly running the model with aphid population density set to 0 at subsequently earlier crop development stages. Initial crop conditions from different field experiments gave estimates of aphid damage at different attainable yield levels. A full account of the procedure was given earlier (Rossing, 1991b). To account for the variation in initial conditions in the field experiments, the model was run with the mean and the mean $\pm 10 \%$, respectively, of all initial conditions. The variation in damage estimates thus obtained is postulated to represent the variation between fields. The relation between the rate of daily damage accumulation per aphid and crop development stage is calculated for three classes of attainable yield using linear regression:

$$
\frac{1}{A} \cdot \frac{\Delta S_{A}}{\Delta t}=\alpha_{3}+\alpha_{4} D
$$

in which $\Delta t$ equals one day, and $S_{A}$ is total aphid damage $\left(\mathrm{kg} \mathrm{ha}^{-1}\right)$.

As no restrictions have been imposed on population density $A$, unrealistically large damage may result at large densities. Therefore, an upper limit for total aphid damage $S_{A}^{\max }\left(\mathrm{kg} \mathrm{ha}{ }^{1}\right)$ is defined. Data of Rabbinge \& Mantel (see Rossing, 199lb) are used to estimate $S_{A}^{\max }$ and its variation.

Damage due to brown rust

Daamen (1991) showed that end-of-season damage by brown rust is related to brown rust stress, defined as the integral of brown rust density over time (sorus-days). Therefore, the rate of damage accumulation is a function of brown rust density. In the range of brown rust intensities of practical interest ( $0-2500$ sorus-days) this function may be simplified to

$$
\frac{1}{B} \cdot \frac{\Delta S_{B}}{\Delta t}=\left\{\begin{array}{cc}
\alpha_{5} Y_{\text {ilt }} & D \leq 83 \\
0 & D>83
\end{array}\right.
$$

in which $\Delta t$ equals 1 day, $S_{B}$ is total damage by brown rust $\left(\mathrm{kg} \mathrm{ha}^{-1}\right)$, and $Y_{\text {att }}$ the attainable yield $\left(\mathrm{kg} \mathrm{ha}{ }^{1}\right)$. After crop development stage DC 83 
brown rust epidemics cause no more damage. To avoid unrealistically large damage at high brown rust intensities, an upper limit for total brown rust damage $S_{B}^{\max }(\mathrm{kg}$ ha ') is defined:

$$
S_{B}^{\operatorname{mix}}=\alpha_{6} Y_{\mathrm{atl}}
$$

An estimate of $\alpha_{6}$ is given by Daamen (1991), based on field experiments in 3 years, with four cultivars.

\section{Financial loss}

Financial loss in an arbitrary field, $L$, is calculated by combining the equations describing damage, and taking the price of winter wheat $w$ (Dfl $\mathrm{kg}^{-1}$ ) and the cost $C$ associated with decision $d_{i}$ in period $i$ into account.

in which

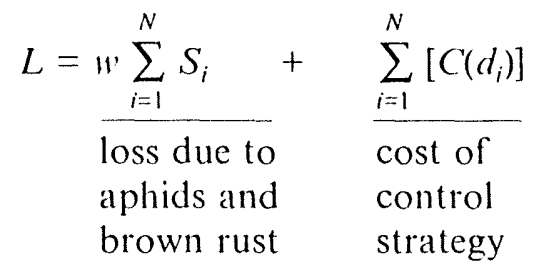

$$
S_{i}=\sum_{\tau=h(i)}^{\mu(i)}\left(\frac{\Delta S_{A}}{\Delta t}+\frac{\Delta S_{B}}{\Delta t}\right)
$$

where $S_{i}$ is damage by aphids and brown rust during decision period $i\left(\mathrm{~kg} \mathrm{ha}^{-1}\right), b(i)$ the first day of decision period $i$ and $l(i)$ the last day of decision period $i$.

The probability distribution of financial loss can be described analytically in terms of the parameters of the probability distributions of the various sources of uncertainty if these latter are sufficiently simple, and if correlations between the variates are known. Alternatively, a Monte Carlo approach can be adopted in which realizations of the simultaneous output distribution of financial loss are generated by simple random sampling from the multivariate input distribution (see Hertz \& Thomas, 1983). Monte Carlo analysis is the more flexible approach as it is independent of the structure of the model and its uncertainty, whereas the analytic approach requires rigorous assumptions on the probability distribution of the sources of uncertainty. A disadvantage of simple random sampling is the large computational effort required for a representative sample of the input space. Latin hypercube sampling (McKay et al., 1979) has been put forward as an equally flexible but more efficient alternative for simple random sampling in Monte Carlo analysis. The increase in efficiency is achieved by stratified sampling ( $M$ strata) from the probability distribution of each input and combining the samples of an input with those of other 
inputs in a random fashion. In this way, a representative picture of the input space is obtained using a relatively small sample. The latin hypercube sampling procedure can be applied to independent inputs with arbitrary probability density functions and to dependent, normally distributed inputs. The procedure results in unbiased estimates of any function of the inputs (Iman \& Conover, 1980; Stein, 1987). For arbitrarily distributed, dependent variates approximations have been proposed by Iman \& Conover (1982). In this paper, latin hypercube sampling is used to estimate the probability distribution of financial loss.

\section{RESULTS}

\section{Quantification of uncertainty about components of the decision model}

\section{Decision variables}

Data on the direct aphicidal effect of pirimicarb vary between 0.36 and 0.99 , depending on the concentration of active ingredient (a.i.) and the habitat of the target organism (Table 1). The effective aphicidal period of pirimicarb is small at $25 \mathrm{~g}$ a.i. ha ${ }^{\prime}$ and varies between 7 and 17 days at higher concentrations (Table 1).

Daamen (1991) concluded that the fungicide triadimefon arrested growth of the brown rust population during approximately 3 weeks while

TABLE 1

Direct Aphicidal Efrect (-) and Efrective Period (day) of Pirimicarb under Field Conditions

\begin{tabular}{|c|c|c|c|c|}
\hline Species & $\begin{array}{c}\text { Dosage } \\
\left(k g \text { a.i.ha }{ }^{\prime}\right)\end{array}$ & $\begin{array}{l}\text { Direct } \\
\text { effect }\end{array}$ & $\begin{array}{c}\text { Effective" } \\
\text { period }\end{array}$ & Reference \\
\hline \multirow{3}{*}{$\begin{array}{l}\text { Metopolophium } \\
\text { dirhodum }\end{array}$} & 0.025 & $0 \cdot 36$ & $<5$ & \multirow{6}{*}{ Poehling (1987) } \\
\hline & $0 \cdot 050$ & 0.86 & $\sim 5$ & \\
\hline & $0 \cdot 150$ & 0.92 & -5 & \\
\hline \multirow[t]{3}{*}{ Sitobion avenae } & 0.025 & 0.94 & $<5$ & \\
\hline & $0 \cdot 050$ & 0.99 & 11 & \\
\hline & $0 \cdot 150$ & 0.99 & 11 & \\
\hline Sitobion arenae & $b$ & $0.93(0.22)^{r}$ & $\sim 7$ & Entwistle \& Dixon (1987) \\
\hline My-us persicae & $0 \cdot 140$ & $0.70-0.88$ & $>7$ & Dewar et al. (1988) \\
\hline
\end{tabular}

"The direct effect is the fraction of the population killed one day after application compared to an untreated control. The effective period is the time interval after application during which the growth rate of the population is negative or approximately zero.

"Pirimicarb, demeton-S-methyl and dimethoate at rates conventional for the UK.

"SEM. 
TABLE 2

Effective Period (day) of Fungicides Used Against Wheat Rusts (Puccinia spp.)

$\left.\begin{array}{llcc}\hline \text { Species } & \text { Active ingredicnt } & \text { Effective period } & \text { Reference } \\ \hline \begin{array}{l}\text { P. recondita on wheat } \\ P . \text { strifformis on wheat }\end{array} & \begin{array}{c}\text { Triadimeton } \\ \text { Propiconazole or } \\ \text { triadimefon } \\ \begin{array}{c}\text { Propiconazole or } \\ \text { triadimefon }\end{array}\end{array} & 21 & \text { Daamen (1991) } \\ & 21-54^{\prime \prime}\end{array}\right\}$ Brown et al. (1986)

"On relatively susceptible cultivars.

"On relatively resistant cultivars.

direct fungicidal effects were negligible. Brown et al. (1986) report similar effects for triadimefon and propiconazole on yellow rust ( $P$. striiformis) on relatively susceptible cultivars (Table 2 ).

In the decision model the uncertainty about the fraction of the population killed as a result of a control decision is described by a Beta distribution. This distribution is defined on the interval $(0,1)$, and is characterized by two parameters, based on mean and variance of $\hat{K}_{x}$.

$$
\hat{K}_{X}\left(d_{i}\right)=\varepsilon_{K_{x},} \quad \varepsilon_{K_{x}} \simeq \operatorname{Beta}\left(a_{X_{*}, d_{i}}, b_{X_{x} d_{i}}\right)
$$

Throughout the analysis a circumflex indicates a prediction while an overbar represents a mean. Uncertainty about the effective periud $P_{X}$ is described by a Normal distribution:

$$
\hat{P}_{X}\left(d_{i}\right)=\bar{P}_{X}\left(d_{i}\right)+\varepsilon_{P_{X},} \quad \varepsilon_{P_{X}} \sim N\left(0, \sigma_{P_{X}\left(d_{i}\right)}^{2}\right) \quad \text { and } \quad \hat{P}_{X}\left(d_{i}\right) \geq 0
$$

Estimates of $a_{X, d_{i}}, b_{x_{\alpha}, d_{i}}, \bar{P}_{X}\left(d_{i}\right)$ and $\sigma_{P_{1}\left(d_{i}\right)}$ for various $d_{i}$ are given in Table 3. The costs of control are assumed fixed (Table 4).

\section{Crop development}

After visual assessment of the data, a negative exponential relation forced through $T=0, D=30$ with an asymptote at crop ripeness (DC 92) was selected to describe the data. Written in linear form, the relation is:

$$
\ln \left(1-\frac{D-30}{D^{\max }-30}\right)=\alpha_{7} T
$$

where $D^{\max }=92$, the maximum crop development stage. Due to lack of distinction between fields in the data, some overestimation of the withinfield variation is expected. However, in view of the good fit $\left(r^{2}=0.98\right)$ this error is negligible. Since variation due to sampling is negligible for both $T$ and $D$, the variation in crop development stage remaining after accounting for the relation with temperature sum represents inherent 
TABLE 3

Probability Distributions and Parameters Describing the Direct Effects $K_{A}\left(d_{i}\right)$ and $K_{B}\left(d_{i}\right)$ (-) and Effective Periods $P_{A}\left(d_{i}\right)$ and $P_{B}\left(d_{i}\right)$ (day) Following Control Decision $d_{i}$ in the Decision Model

\begin{tabular}{|c|c|c|c|c|c|c|c|c|}
\hline \multirow[t]{2}{*}{$d_{i}^{\prime \prime}$} & \multicolumn{2}{|c|}{$K_{.1}\left(d_{1}\right)$} & \multicolumn{2}{|c|}{$P_{.1}\left(d_{i}\right)$} & \multicolumn{2}{|c|}{$K_{B}\left(d_{i}\right)$} & \multicolumn{2}{|c|}{$P_{B}\left(d_{i}\right)$} \\
\hline & $\begin{array}{c}\text { distrihu- } \\
\text { tion }\end{array}$ & parameters & $\begin{array}{c}\text { distribu- } \\
\text { tion }\end{array}$ & parameters & $\begin{array}{l}\text { distribu- } \\
\text { tion }\end{array}$ & parameters & $\begin{array}{l}\text { distribu- } \\
\text { tion }\end{array}$ & parameters \\
\hline 1 & Beta" & $0,1^{\circ}$ & Normald & $0,0^{r}$ & Beta & $0, \mathrm{I}^{\circ}$ & Normal $^{d}$ & $0,0^{c}$ \\
\hline 2 & Beta & $2 \cdot 93,0.52$ & Normal & $12,0 \cdot 20$ & Beta & $0, \mathrm{I}^{\circ}$ & Normal & $0,0^{\circ}$ \\
\hline 3 & Beta & $0,1^{c}$ & Normal & $0,0^{r}$ & Beta & $0,1^{\circ}$ & Normal & $18,0 \cdot 20$ \\
\hline 4 & Beta & $2 \cdot 93,0.52$ & Normal & $12,0 \cdot 20$ & Beta & $0,1^{\circ}$ & Normal & $18,0 \cdot 20$ \\
\hline
\end{tabular}

" $d_{i}=1$ : no chemical control; $d_{i}=2$ : aphicide application; $d_{i}=3$ : fungicide application; $d_{i}=4:$ mixed aphicide and fungicide application.

"Parameters of the Beta distributions represent $a_{X_{d} d_{i}}$ and $a_{X_{\alpha} / i}$, respectively.

"Dummy values: fraction of population killed equals zero.

"Paramcters of the normal distributions represent mean and coefficient of variation, respectively.

system randomness which is described as 'white noise'. In the decision model, $\alpha_{7}$ is predicted as

$$
\hat{\alpha}_{7}=\overline{\alpha_{7}}+\varepsilon_{\kappa \gamma_{7}}, \quad \varepsilon_{\alpha_{7}} \simeq N\left(0, \sigma_{\alpha_{7}}^{2}\right)
$$

Least squares estimates of $\overline{\alpha_{7}}$ and $\sigma_{r x_{7}}$ are -0.0031 and 0.000065 , respectively $(n=44)$. In addition to the uncertainty about $\alpha_{7}$, white noise has to be accounted for in the prediction of crop development stage:

$$
\ln \left(1-\frac{D-30}{D^{\operatorname{mix}}-30}\right)=\hat{\alpha}_{7} T+\varepsilon_{W: D}, \quad \varepsilon_{W^{\prime}, D} \simeq N\left(0, \sigma_{c, D}^{2}\right)
$$

in which $\sigma_{c, D}^{2}$ is the residual variance $\left(\hat{\sigma}_{c, D}^{2}=0.012\right)$. The data and the fitted relation are shown in Fig. 3A. Extrapolation is required to arrive

TABLE 4

Costs (Dfl ha') Ascociated with Chemical Control of Aphids and/or Brown Rust in Winter Wheat (based on Drenth \& Stol, 1990)

\begin{tabular}{lccccc}
\hline Control target & Labour \& machinery" & Wheeling damage & Aphicidec $^{\prime}$ & Fungicide $^{\prime}$ & Total \\
\hline Aphids & 40 & 45 & 30 & - & 115 \\
Brown rust & 40 & 45 & - & 70 & 155 \\
Aphids and & 40 & 45 & 30 & 70 & 185 \\
\hline
\end{tabular}

"Contract labour.

"No fixed wheeltracks, spray after mid May, sprayswath with $11 \mathrm{~m}$.

"Based on Pirimor.

"Based on Baylidan, Corbel or Tilt. 

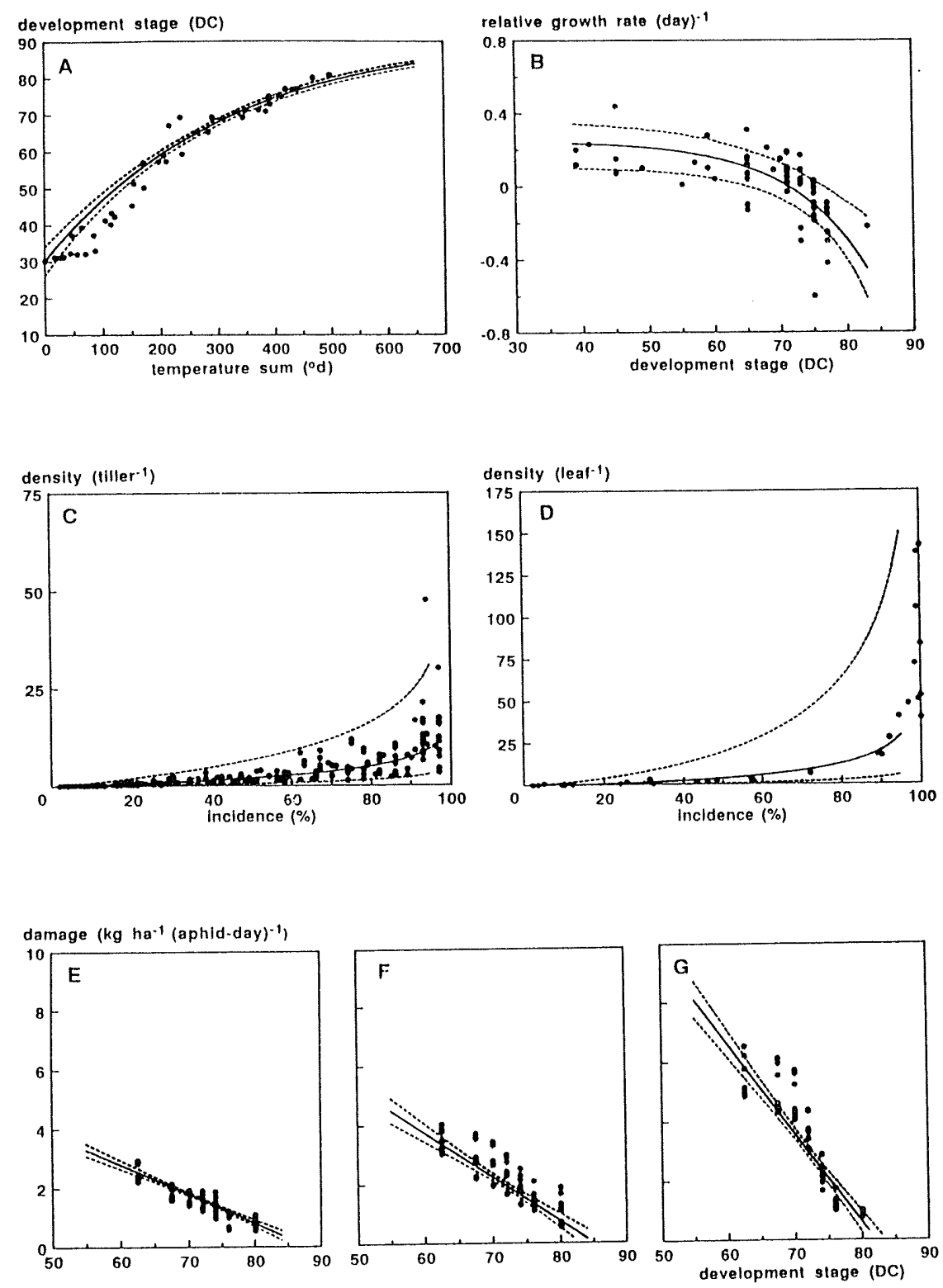

Fig. 3. Overview of the mathematical relations in the decision model and the $95 \%$ confidence interval due to parameter uncertainty. Uncertainty due to sampling and white noise is not shown. A: eqn (11); B: eqn (14); C: eqn (3), aphids; D: eqn (3), brown rust; E: eqn (4), 3500-6000 kg hal ': F: eqn (4), 6000 9000 kg ha '; G: eqn (4), 9000 $10000 \mathrm{~kg}$ ha '. 
TABLE 5

Maximum Likelihood Estimates of $\alpha_{x} \alpha_{y}$ and $\alpha_{10}$ in eqn (14), Describing the Relation Between the Relative Growth Rate of the Cereal Aphid Population and Crop Development Stage

\begin{tabular}{ccrcc}
\hline Parameter & Estimate & \multicolumn{3}{c}{ Covariance matrix } \\
\hline$\alpha_{8}$ & 0.25 & 0.004913 & & \\
$\alpha_{9}$ & 0.087 & -0.001565 & 0.000749 & \\
$\alpha_{10}$ & -0.19 & -0.004924 & 0.001923 & 0.005657 \\
\hline
\end{tabular}

Maximum likelihood estimates of the between-field standard deviation $\sigma_{a x, y}$ and the within-field standard deviation $\sigma_{\mathrm{e}, / t}$ are 0.053 and 0.133 , respectively. The fraction of the variation explained, $r^{2}$, is 0.32 and the number of data points, $n$, is 59 .

in DC 83, the end of the planning horizon. The parameter $\alpha_{7}$ is predicted at the start of each Monte Carlo run. Realizations of $\varepsilon_{\text {II: } D}$ are calculated each time crop development stage is predicted.

\section{Population growth of aphids and brown rust}

Preliminary analysis of the cereal aphid data showed a significant effect of crop development stage, both as a linear and as a quadratic term, on the relative growth rate $r_{A}$. Since an increase of the relative growth rate with crop development stage is biologically improbable (e.g. Carter et al., 1982), a monotone function was preferred. Therefore, the relative growth rate was modelled as a function of crop development stage according to

$$
r_{A}=\alpha_{8}+\alpha_{10} \exp \left(\alpha_{9}(D-68)\right)
$$

in which 68 is an offset, approximately equal to the mean value of $D$ in the data. The parameters $\alpha_{9}$ and $\alpha_{10}$ which determine the shape of the curve, were found to be independent of year and cultivar $(p>0 \cdot 1)$. The parameter $\alpha_{8}$ which describes the level of the curve, however, differed significantly $\left(F_{13.43}=2.71, n=59, p<0.01\right)$ between year-field combination. Fitted parameter values are shown in Table 5.

The contribution of sampling error to the residual variation in the relative growth rate was assessed using a Taylor expansion to estimate the sampling variance of $r_{A}$. The relation between mean and variance of a density estimate was calculated from the coefficient of variation. Sampling variance constitutes at most approximately $10 \%(0.0016)$ of the residual variance $\left(\sigma_{t, r}^{2}, 0.018\right)$. Thus, variation due to sampling is negligible and the residual variation is modelled as a white noise process.

In the decision model, a prediction of the mean daily relative growth 
rate of aphids is made using eqn (14) and predicting $\alpha_{8}, \alpha_{9}$ and $\alpha_{10}$ according to

$$
\left(\begin{array}{c}
\hat{\alpha}_{8} \\
\hat{\alpha}_{9} \\
\hat{\alpha}_{10}
\end{array}\right)=\left(\begin{array}{c}
\bar{\alpha}_{8} \\
\bar{\alpha}_{10} \\
\bar{\alpha}_{10}
\end{array}\right)+\varepsilon_{v_{r_{1}, 1}} \quad \varepsilon_{\alpha_{r, 1}} \simeq N_{3}\left(0, \Sigma_{1}\right)
$$

in which $\Sigma_{1}$ is the covariance matrix of $\alpha_{8}, \alpha_{9}$ and $\alpha_{10}$. Random deviation from the level $\hat{\alpha}_{8}$ in an arbitrary field results in a field-specific estimate $\hat{\alpha}_{8, f}$ :

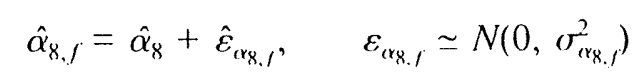

White noise in the growth rate of the aphid population is accounted for by predicting $r_{A}$ according to

$$
\hat{r}_{A}=\hat{\alpha}_{8, f}+\hat{\alpha}_{11)} \exp \left(\hat{\alpha}_{9}(D-68)\right)+\varepsilon_{W, r_{A},} \quad \varepsilon_{W, r_{A}} \simeq N\left(0, \sigma_{e, r_{A}}^{2}\right)
$$

Maximum likelihood estimates of $\bar{\alpha}_{8}, \bar{\alpha}_{9}, \bar{\alpha}_{10} \Sigma_{1}, \sigma_{\alpha_{\mathrm{x}, 1}}^{2}$ and $\sigma_{r^{\prime}, r_{a}}^{2}$ are given in Table 5. The fitted relation is shown in Fig. 3B. The parameters $\alpha_{8, f}$, $\alpha_{9}$ and $\alpha_{10}$ are predicted at the start of each Monte Carlo run. Realizations of $\varepsilon_{W^{\prime}, r_{A}}$ are calculated once every 7 days, commensurate with the time scale of white noise in the data.

Analysis of variance of the brown rust data indicated no significant effects of year, cultivar, crop development stage or location on the relative growth rate $r_{B}$. The relative growth rates in subsequent intervals of 14 days appeared to vary independently. The contribution of sampling to the variation in the relative growth rate was assessed using the empirical relation between mean density and variance given by Daamen (1991). As for aphids, sampling variance was approximately $10 \%$ of the residual variance of the relative growth rate of brown rust. For prediction of the population growth rate the residual variance must be taken into account as white noise.

In the decision model, a prediction of the mean daily relative growth rate is made according to

$$
\hat{r}_{B}=\bar{r}_{B}+\varepsilon_{W, r_{B},}, \quad \varepsilon_{W, r_{B}} \simeq N\left(0, \sigma_{\varphi, r_{B}}^{2}\right)
$$

Estimates of $\bar{r}_{B}$ and $\sigma_{C, r_{B}}^{2}$ are 0.163 and 0.0066 , respectively $(n=25)$. The variance of $\bar{r}_{B}(0.00026)$ is negligible in comparison with $\sigma_{c, r_{B}}^{2}$, and is disregarded. In the model, realizations of $\varepsilon_{W^{\prime}, r_{B}}$ are calculated at intervals of 14 days, commensurate with the time scale of white noise in the data.

Incidence-density relations of aphids and brown rust

Daamen (1991) found no significant effect of year, cultivar, crop development stage or location on the incidence-severity relation for brown rust. Although for aphids no information on co-variables was 
available, it is assumed that these have no effect on the relation. This assumption is supported by results of Ward et al. (1986) who found no effect of co-variables based on one year's data on $S$. avenae from Sussex, England. Because both incidence and density were assessed accurately, the imperfect fit of eqn (3) is due to white noise.

In the decision model, a prediction of cereal aphid and brown rust density at given incidence is made using eqn (3) and predicting $\hat{\alpha}_{1, X}$ and $\hat{\alpha}_{2, x}$ according to

$$
\left(\begin{array}{l}
\hat{\alpha}_{1, X} \\
\hat{\alpha}_{2, Y}
\end{array}\right)=\left(\begin{array}{l}
\bar{\alpha}_{1, X} \\
\bar{\alpha}_{2, X}
\end{array}\right)+\varepsilon_{\alpha 1,2, Y,}, \quad \varepsilon_{\alpha 1,2, X} \simeq N_{2}\left(0, \Sigma_{X}\right)
$$

in which $\Sigma_{X}$ is the covariance matrix of $\alpha_{1, X}$ and $\alpha_{2, X}$. In addition to the uncertainty about the parameter estimates, white noise has to be accounted for in the predicted density:

$$
\widehat{\ln \left(X_{0}\right)}=\hat{\alpha}_{1, X}+\bar{\alpha}_{2, X} \ln \left(\ln \left(\frac{1}{1-\hat{I}_{X}}\right)\right)+\varepsilon_{W, X}, \quad \varepsilon_{W, X} \simeq N_{2}\left(0, \sigma_{e, X}^{2}\right)
$$

in which $\sigma_{c, X}^{2}$ is the residual variance for aphids and brown rust. Finally, uncertainty exists about $I_{X}$ due to the farmer's sample estimate $I_{0, X}$

$$
\hat{I}_{X}=\varepsilon_{I, X}, \quad \varepsilon_{I X} \simeq \operatorname{Binomial}\left(I_{0, X}, n_{X}\right)
$$

where $n_{X}$ represents the number of units in a sample. Least squares estimates of $\bar{\alpha}_{1, X}, \bar{\alpha}_{2, Y}, \Sigma_{X}$ and $\sigma_{e, X}^{2}$ are given in Table 6 for aphids and brown rust. The fitted relations are shown in Fig 3C-D. Predictions of In $\left(X_{0}\right)$ need be made at the onset of each Monte Carlo run, only. Since $n_{X}$ is approximately 100 , the binomial error distribution of eqn (21) is approximated by a normal distribution with mean $I_{0, X}$ and variance $I_{0, X}$ $\left(1-I_{0, X}\right) / n_{x}$, truncated at 0 .

\section{TABLE 6}

Least Squares Estimates of $\alpha_{1, A}$ and $\alpha_{2, A}$ Concerning Aphids and $\alpha_{1, B}$ and $\alpha_{2, B}$ Concerning Brown Rust in eqn (3), Describing the Relation Between Density and Incidence

\begin{tabular}{ccc}
\hline Parameter & Estimate & Standard error \\
\hline$\alpha_{1 . A}$ & 1.11 & 0.039 \\
$\alpha_{2 ., 1}$ & 1.05 & 0.027 \\
$\alpha_{1 . B}$ & 1.84 & 0.14 \\
$\alpha_{2 ., B}$ & 1.39 & 0.08 \\
\hline
\end{tabular}

Additional Statistics for cereal aphids: $r^{2}=0.87$, residual error $\hat{\sigma}_{t, A}=0.524, n=226$. Additional statistics for leaf rust: $r^{2}=0.91$, residual error $\hat{\sigma}_{e^{\prime}, B}=0.79, n=31$. Estimated covariances are $\operatorname{cov}\left(\alpha_{1, A}, \alpha_{2, A}\right)=0.000484$ and $\operatorname{cov}\left(\alpha_{1, B}, \alpha_{2, B}\right)=-0.000314$. 
Damage due to aphids

In the decision model damage per aphid-day at given crop development stage is predicted using eqn (4) and predicting $\hat{\alpha}_{3}$ and $\hat{\alpha}_{4}$ according to

$$
\left(\begin{array}{c}
\hat{\alpha}_{3} \\
\hat{\alpha}_{4}
\end{array}\right)=\left(\begin{array}{c}
\bar{\alpha}_{3} \\
\bar{\alpha}_{4}
\end{array}\right)+\varepsilon_{w_{1,4}}, \quad \varepsilon_{w_{3,4}} \simeq N_{2}\left(0, \Sigma_{2}\right)
$$

in which $\Sigma_{2}$ is the covariance matrix of $\alpha_{3}$ and $\alpha_{4}$. Least squares estimates of $\alpha_{3}$ and $\alpha_{4}$ and their variances are shown in Table 7 for three classes of attainable yield. The fitted relations are shown in Fig. $3 \mathrm{E}-\mathrm{G}$. In the decision model, extrapolation to DC 55 and DC 83, respectively, is required. A curvilinear model might have resulted in a better fit for the class with highest attainable yields (Fig. $3 \mathrm{G}$ ). In view of the simulation origin of the data a common approach was preferred.

Maximum aphid damage is predicted according to

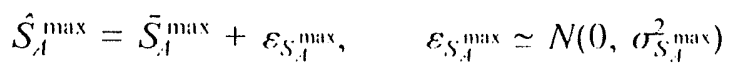

Based on the available data, $\bar{S}_{i}^{\max }$ is estimated to be $1890 \mathrm{~kg}$ ha ${ }^{\prime}$. The standard error $\sigma_{S}^{\text {max }}$ is taken to be $200 \mathrm{~kg}$ ha ', approximately $10 \%$ of the estimated mean. The parameters $\alpha_{3}, \alpha_{4}$ and $S_{\text {. }}^{\text {max }}$ are predicted at the start of each Monte Carlo run.

Damage due to brown rust

In the decision model, damage per sorus-day is predicted using eqn (5) in which

$$
\hat{\alpha}_{5}=\bar{\alpha}_{5}+\varepsilon_{w_{s}}, \quad \varepsilon_{\omega_{5}} \simeq N\left(0, \sigma_{v_{s}}^{2}\right)
$$

Estimates of $\bar{\alpha}_{5}$ and $\sigma_{\text {ors }}$ are $0.00014 \mathrm{~kg} \mathrm{~kg}{ }^{\prime}$ and $0.000036 \mathrm{~kg} \mathrm{~kg}{ }^{\prime}$, respectively $(n=3$; Daamen, 1991). Maximum brown rust damage is calculated using eqn (6) where

$$
\hat{\alpha}_{6}=\varepsilon_{\alpha_{6},}, \quad \varepsilon_{i^{\prime \prime}} \simeq \operatorname{Beta}\left(a_{\alpha_{\sigma_{6}}}, b_{\left.n_{6}\right)}\right)
$$

The Beta distribution conveniently describes the fraction $\alpha_{6}$, characterized by mean $\bar{\alpha}_{6}$ and variance $\sigma_{\alpha_{6}}^{2}$. The parameters $a_{\alpha_{\sigma_{6}}}$ and $b_{\alpha_{6}}$ are estimated to be 25.86 and 60.25 , based on $\bar{\alpha}_{6}=0.30 \mathrm{~kg} \mathrm{~kg}{ }^{1}{ }^{\prime}(n=3$; Daamen, 1991) and $\sigma_{\alpha_{6}}=0.05 \mathrm{~kg} \mathrm{~kg}$. The latter estimate is based on the experience that in The Netherlands brown rust rarely causes yield reductions higher than $40 \%$. The parameters $\alpha_{5}$ and $\alpha_{6}$ are predicted at the start of each Monte Carlo run.

\section{Calculation of the probability distribution of model output}

For a given initial state of the system described by temperature sum $\left(T_{0}\right)$ and observed incidences of aphids $\left(I_{0 . \wedge}\right)$ and brown rust $\left(I_{0, B}\right)$, and for a 


\section{TABLE 7}

Least Squares Estimates of $\alpha_{3}$ and $\alpha_{4}$ in Eqn (4), Describing the Relation Between Aphid Damage and Crop Development Stage for Three Classes of Attainable Yield

\begin{tabular}{|c|c|c|c|}
\hline richld classs & Parame'ter & Estimate' & Standard error \\
\hline \multirow[t]{2}{*}{350066000} & $\alpha_{3}$ & 8.81 & 0.435 \\
\hline & $\alpha_{4}$ & $-0 \cdot 10$ & 0.006 \\
\hline \multirow[t]{2}{*}{60009000} & $\alpha_{3}$ & 12.75 & 0.845 \\
\hline & $\alpha_{4}$ & $-0 \cdot 15$ & 0.012 \\
\hline \multirow{2}{*}{$9000 \quad 10000$} & $\alpha_{3}$ & $24 \cdot 60$ & 1.269 \\
\hline & $\alpha_{4}$ & $-0 \cdot 30$ & 0.018 \\
\hline
\end{tabular}

Additional statistics for yield class $3500-6000 \mathrm{~kg} \mathrm{ha}: r^{2}=0.82$, residual crror $\hat{r}_{t}=0.25, n=62$. Estimated covariance is $\operatorname{cov}\left(\alpha_{3}, \alpha_{4}\right)=-0.00262$. For yield class $6000-9000 \mathrm{~kg} \mathrm{ha}{ }^{\prime}: r^{2}=$ 0.72, residual crror $\hat{\sigma}_{e^{\prime}}=0.49, n=62, \operatorname{cov}\left(\alpha_{3}, \alpha_{4}\right)=-0.00992$. For yicld class $9000-10000 \mathrm{~kg}$ ha $! r^{2}=0.82$, residual error $\hat{\sigma}_{t^{\prime}}=0.74, n=62, \operatorname{cov}\left(\alpha_{3,}, \alpha_{4}\right)=-0.0223$.

particular decision strategy $\left\{d_{1}, \ldots, d_{N}\right\}, M$ Monte Carlo runs are made. During a run the dynamics of the state of the system are calculated by discrete simulation with time steps of one day. A run ends at crop development stage DC 83 as from then on no more loss occurs. Thus, each run represents the realization of a crop-pest and crop-disease interaction during a growing season in an arbitrary field. In total, $M$ of these cases, i.e. year-field combination, are simulated. At the start of each Monte Carlo run a stratified sample is drawn from the appropriate probability distributions of daily maximum and minimum temperatures, incidence sample estimates and each of the parameters, respectively. A stratum of daily maximum and minimum temperatures is equated with a temperature series of 1 year. Since 36 years of temperature data are available, a year's data are used more than once when $M$ exceeds 36 . In the course of a Monte Carlo run, realizations of the sources of white noise $\varepsilon_{\|: D}$ (eqn 13), $\varepsilon_{\|, r_{A}}$ (Eqn 17) and $\varepsilon_{\|, r_{B}}$ (eqn 18) are drawn from their probability distributions at time intervals commensurate with the data. The algorithm is programmed in FORTRAN-77 using IMSL routines (IMSL, 1987) and runs on a VAX 8700 mainframe.

A suitable value of $M$ represents a compromise between the precision of the estimated probability distribution and the computational effort (Stein, 1987). Preliminary runs with $M=300$ and $M=500$ were compared to a 'reference', consisting of a simple random sample with $M=3000$. Both for $M=300$ and $M=500$ differences in means and variances with $M=3000$ were small. However, latin hypercube sampling 

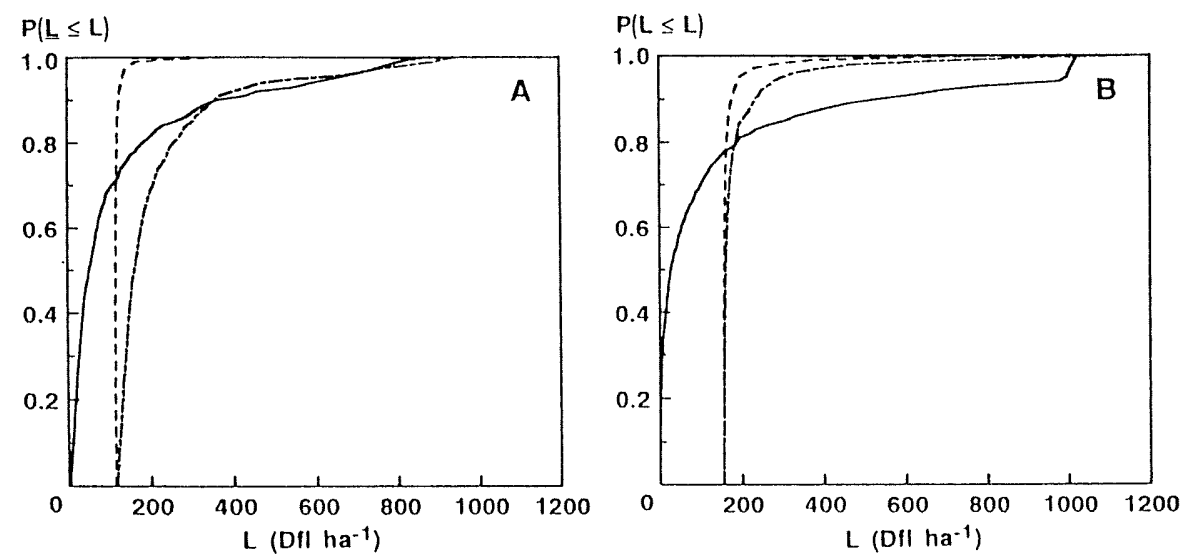

Fig. 4. Estimated cumulative probability density curves of financial loss for three different tactics of control of aphids $(A)$ and brown rust $(B)$. Attainable yick is $8000 \mathrm{~kg}$ ha! Initial conditions during calculations were: $I_{0.1}=0.25 ; I_{0, B}=\left(0.02 ; \mathrm{T}_{0}=225^{\circ} \mathrm{d}\right.$ on day of the year 169 . As a result $D_{0}=61(s d=4)$. Tactics comprise no chemical control in any decision period (NS) (....). spray at the start of the first decision period only (S1) (- - ), and spray at the start of the fourth decision period only (S4) (.........

with $M=500$ was found to produce probability density distributions with tails rather similar to the reference on visual inspection. As this sample size was technically feasible, $M=500$ was selected.

\section{Estimated cumulative probability density functions of financial loss}

To illustrate the output of the decision model, estimated cumulative probability density functions of financial loss are shown in Fig. 4 for three strategies of control of aphids and brown rust. Some statistics are listed in Table 8. Compared to no chemical control in any decision period (NS) or chemical control at the start of the fourth decision period only (S4), chemical control at the start of the first decision period only (S1) decreases the frequency of occurrence of large financial losses for both aphids and brown rust. The least financial loss that may be incurred is approximately zero when no chemical control is carried out, while it approximately equals the costs of the control operation (see Table 4) when a chemical is applied. As a result, the probability density function of financial loss associated with immediate chemical control (S1) is narrower than the probability density function associated with no chemical control (NS) or postponed control (S4).

The initial conditions in the example have been chosen such that the mean financial losses of no chemical control and immediate chemical control are approximately equal, for both aphids and brown rust (Table 8). 
TABLE 8

Statistics Describing Financial Loss for Three Different Strategies of Control of Aphids and Brown Rust. Initial Conditions are Given in the Caption of Fig. 4.

Aphids

\begin{tabular}{lcrccccc}
\hline Stratcgy & Mcem & \multicolumn{1}{c}{ sd } & Skemmess & Kurtosis & $p_{0.90}$ & Range & Deterministic loss \\
\hline NS & 115 & 183 & 2.6 & 6.0 & 317 & 864 & 27 \\
SI & 121 & 23 & 8.8 & $81 \cdot 2$ & 125 & 225 & 117 \\
S4 & 205 & 150 & 3.3 & 11.4 & 319 & 824 & 141 \\
\hline
\end{tabular}

Brown rust

\begin{tabular}{lcrcrrrr}
\hline Strategy, & Me'an & sd & Skewness & Kurtosis & $p_{0.90}$ & Range & Deterministic loss \\
\hline NS & 127 & 245 & 2.6 & $5 \cdot 7$ & 417 & 1021 & 29 \\
S1 & 165 & 35 & $9 \cdot 0$ & $100 \cdot 1$ & 174 & 497 & 157 \\
S4 & 191 & 104 & 6.2 & 45.8 & 237 & 1010 & 162 \\
\hline
\end{tabular}

Strategies comprise no chemical control in any decision period (NS), spray on the first day of the first decision period only (SI), and spray on the first day of the fourth decision period only (S4). In the last column financial loss calculated with the deterministic model version is shown.

Thus, these initial conditions represent a damage threshold, i.e. conditions at which chemical control should be carried out. The probability density functions of no chemical control and immediate chemical control intersect at one point, which represents the fraction of cases in which the former strategy results in smaller financial loss than the latter. Fig. 4 shows that at this damage threshold no chemical control would result in smaller financial loss than immediate chemical control in approximately $75 \%$ of the cases evaluated, for both aphids and brown rust.

In the deterministic decision model, parameters and inputs are set to their average values and white noise is assumed absent. Deterministic financial losses associated with no chemical control (NS) or postponed chemical control (S4) are considerably smaller than stochastic results (Table 8). For immediate chemical control (S1) results of the stochastic and deterministic models are similar, reflecting the smaller degree of uncertainty about financial loss.

\section{Damage thresholds}

Damage thresholds for aphids and brown rust have been calculated separately for a range of crop development stages using the deterministic and the stochastic version of the decision model (Fig. 5). Lower damage threshold values imply that chemical control should be carried out at 

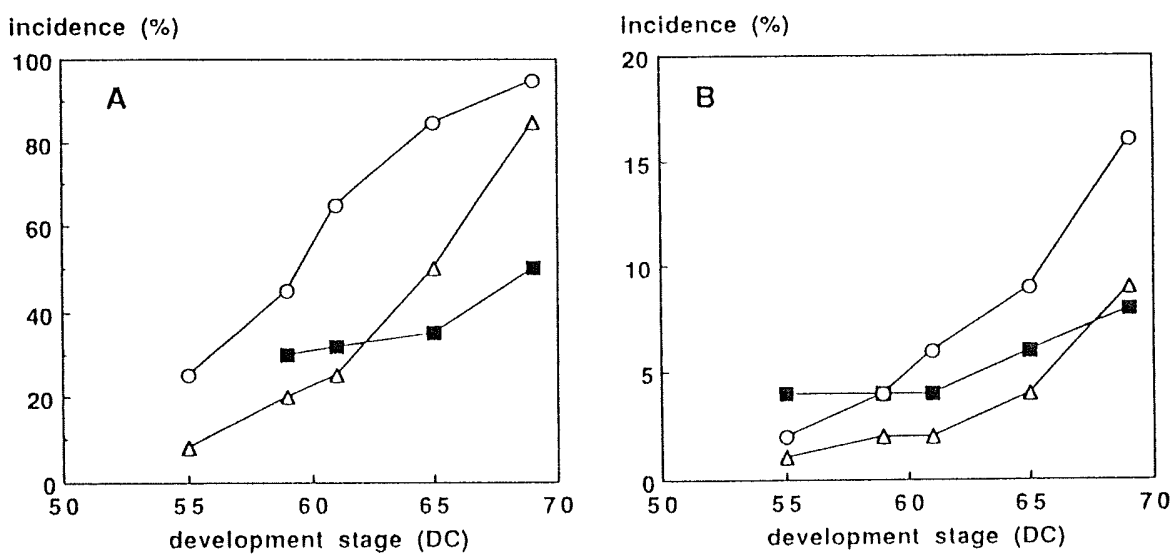

Fig. 5. Damage thresholds for aphids $(A)$ and brown rust $(B)$ according to EPIPRE (-) the deterministic version of the decision model $(O$.$) and the stochastic$ version, run with $M=500(-\Delta)$. EPIPRE damage thresholds were calculated assuming four green leaves per plant al all crop development stages. Attainable yield is $8000 \mathrm{~kg}$ ha'. The decision evaluation model was initialised with the following combinations of temperature sum $\left({ }^{\circ} \mathrm{d}\right)$ and day of the year: DC 55: 165, 161: DC 59: 200), 164: DC 61: 225 . 166; DC: 265, 169; DC 69: 320. 172. Crop development stages for the thresholds of the stochastic model represent means of 50$)(0)$ runs.

lower pest and disease incidences, which is usually equivalent to earlier in time. The damage thresholds calculated with the deterministic version exceed those calculated with the stochastic version both for aphids and for brown rust. Thus, uncertainty causes chemical control to become economical at lower pest and disease incidences, which may lead to higher pesticide use.

Also shown in Fig. 5 are the damage thresholds for aphids and brown rust according to EPIPRE (Drenth \& Stol, 1990). For aphids, the EPIPRE thresholds are lower than the stochastic thresholds from flowering onward. For brown rust the EPIPRE thresholds are slightly higher than the deterministic thresholds from DC 55 until shortly before the end of flowering (DC 69), when the two measures coincide.

\section{DISCUSSION}

No formal validation of the decision model has been attempted. Nevertheless, the foundation of the model in EPIPRE, which has been evaluated extensively (Reinink, 1986; Drenth \& Stol, 1990), and the availability of a relatively large set of ficld data for updating and upgrading (sensu Rabbinge, 1988) convey trust in the relevance of the model for practical supervised control of the multiple pathosystem winter wheat- 
aphids-brown rust. Updating has involved revision of all mathematical relations, partly because new information has become available (Daamen, 1991; Rossing, 1991 b), and, more importantly, because previously interest has never been in analysing the uncertainty. Upgrading concerned the introduction of daily temperatures and the relation between temperature sum and crop development stage. The data used to quantify the latter relation were collected during 1 year in the UK. Although this data base is rather narrow, the predictions of the model are similar to the relation between time and crop development stage used in EPIPRE (Drenth \& Stol, 1990) which represents a long-term average for The Netherlands.

Compared to immediate chemical control the expected financial loss of no chemical control shows the larger deviation from the deterministic value. This is caused by the larger range of possible outcomes in combination with the long right tails of the probability distribution (Fig. 4 and Table 8). It explains why the damage thresholds calculated with the deterministic version of the model exceed those calculated with the stochastic version at all crop development stages evaluated for both aphids and brown rust (Fig. 5). The size of the difference between the deterministic and the stochastic thresholds reflects 'the price of uncertainty', the degree to which uncertainty contributes to earlier spraying at current prices of wheat and agro-chemicals. The size of the difference increases with advancing crop development stage for brown rust. For aphids the difference decreases at later crop development stages because a maximum population density is reached (and $r_{A}=0$, Fig. 3B) before the end of the planning horizon. In conclusion, taking uncertainty about predicted costs and benefits of chemical control into account appears necessary, even without reference to the risk-attitude of the decision maker.

The stochastic damage thresholds represent those pest and disease incidences at which a risk-neutral decision maker, who is interested in average costs and benefits only, would just apply a chemical. Compared to the risk-neutral stochastic damage thresholds, the EPIPRE thresholds for aphids are risk-neutral to risk-avoiding, i.e. equal to or lower than the stochastic damage thresholds, while those for brown rust are slightly risk-seeking to risk-neutral, i.e. higher than or equal to the stochastic damage thresholds. Entwistle \& Dixon (1987) also pointed out that the EPIPRE thresholds for aphids apparently implicitly assume a farmer to behave in a risk-averse manner. An alternative to giving a recommendation in which risk is implicitly accounted for (see Mann \& Wratten, 1989), is to present information on the risk associated with different decision alternatives. Such explicit presentation of the consequences of uncertainty, advocated by Tait (1987), is addressed elsewhere (Rossing et al., 1994a). 
Uncertainty about model structure is beyond the scope of this study. During development of the model, mathematical relations which best described the data (highest $r^{2}$ and smallest residual variance) have been preferred over alternative formulations. In two cases, alternatives have been rejected on different grounds. The first structural alternative is due to Entwistle \& Dixon (1987), who proposed a multiple regression equation to describe aphid damage as a function of aphid density and population growth rate. The model is currently not used due to incomplete information on its uncertainty. However, when complete, it should be preferred over the current relation, since the latter is based on simulated data presumably representing the variation in the field. The second structural alternative concerns the stochastic model for the relative growth rate of aphids. During data analysis a model of similar structure to eqn (14), but with the residual variance increasing with crop development stage, was found to describe the data as well as eqn (17). After fitting the model, the between-field variation in the parameters $\alpha_{8}, \alpha_{9}$ and $\alpha_{10}$ appeared insignificant. Ecologically, however, the variation in the relative growth rate is unlikely to increase with crop development stage because cereal aphid populations consistently reach peak densities around DC 75-77 and subsequently collapse. Variation between fields, on the other hand, is ecologically highly plausible due to factors like micro-weather and natural enemies which may vary between fields (Entwistle \& Dixon, 1986, 1987). For these reasons the more complex stochastic model has been preferred in the decision model.

In a theoretical study on parameter uncertainty, Kremer (1983) raised the question whether parameters should be treated as constant but poorly known or as inherently stochastic and varying in time. Using a simple model of algal competition he demonstrated that the two concepts may yield greatly different results. Although Kremer's results depended strongly on the simple nature of his model which contained few feedbacks, the issue has received attention from other authors (see e.g. Beck, 1987). Reports on application of the two concepts in realistic ecological models appear rare, however. In this study, variation in the data which is not accounted for by regression is attributed to sampling of the dependent variable, resulting in the concept of a parameter being constant but poorly known. In the five cases where the contribution of sampling to residual variation could be quantified (equs (3)-both for aphids and brown rust-(13), (17) and (18)) it has been found to be insignificant. In those cases, the residual variation is described as a part of the system, causing the parameters to vary in time. Such white noise is to be expected as not all factors influencing the dependent variable have been included in the regression equation and many of them may vary in time. 
To the best of our knowledge this study is the first report of actual quantification of white noise in an ecological study using empirical data to estimate the size and the frequency of variation in parameters.

The degree to which the various sources of uncertainty in the decision model contribute to the uncertainty about financial loss is analysed in a following contribution (Rossing et al., 1993a).

\section{ACKNOWLEDGEMENTS}

Thanks are due to Professors P. van Beek, R. Rabbinge and J. C. Zadoks for comments on an earlier version of the manuscript.

\section{APPENDIX 1. DEFINITION OF SYMBOLS}

\section{State variables}

$\begin{array}{lll}\text { Symbol } & \text { Definition } & \text { Initial value } \\ A & \text { Aphid density } & A_{0} \text { tiller }^{-1} \\ B & \text { Brown rust density } & B_{0} \text { leaf }^{-1} \\ D & \text { Crop development stage } & D_{0} \\ S_{A} & \text { Aphid damage } & 0 \mathrm{~kg} \mathrm{ha}^{-1} \\ S_{B} & \text { Brown rust damage } & 0 \mathrm{~kg} \mathrm{ha}^{-1} \\ S_{i} & \text { Damage in decision period } i & 0 \mathrm{~kg} \mathrm{ha}^{-1} \\ T & \text { Temperature sum since DC } 30 & T_{0}^{\circ} \mathrm{C} \text { day } \\ L & \text { Financial loss } & 0 \mathrm{Dfl} \mathrm{ha}\end{array}$

\section{Other variables and parameters}

\begin{tabular}{|c|c|c|}
\hline Symbol & Definition & Unit \\
\hline$a_{A, k i} b_{A, \alpha i}$ & Parameters describing the variation in $K_{A}$ &,-- \\
\hline$a_{B_{. d l_{i}}} b_{B_{3 . d_{i}}}$ & Parameters describing the variation in $K_{B}$ &,-- \\
\hline$a_{\alpha r s}, b_{\alpha r s}$ & $\begin{array}{l}\text { Parameters describing the variation in } \\
\text { parameter } \alpha_{6}\end{array}$ &,-- \\
\hline$b(i)$ & First day of decision period $i$ & - \\
\hline$C$ & Costs associated with a control decision & Dfl ha ${ }^{-1}$ \\
\hline$d_{i}$ & Control decision in decision period $i$ & - \\
\hline$D^{\max }$ & Maximum crop development stage & - \\
\hline$I_{A}$ & Aphid incidence & - \\
\hline$I_{0, A}$ & Observed aphid incidence & - \\
\hline$I_{B}$ & Brown rust incidence & \\
\hline
\end{tabular}




Symbol
$I_{0 . B}$
$K_{A_{\left(d_{i}\right)}}$
$K_{b_{(}\left(d_{i}\right)}$

l(i)

$M$

$n_{A}$

$n_{B}$

$N$

$P_{A}$

$P_{B}$

$r_{A}$

$R_{A}$

$r_{B}$

$R_{B}$

$S_{4}^{\max }$

$S_{B}^{\text {max }}$

$t$

$t^{\prime \prime}$

"'

$Y_{\text {utt }}$

$\alpha_{1, A}, \alpha_{2, A}$

$\alpha_{1, B}, \alpha_{2, B}$

$\alpha_{3}, \alpha_{4}$

$\alpha_{5}$

$\alpha_{6}$

$\alpha_{7}$

$\alpha_{8}, \alpha_{9}, \alpha_{10}$
Definition

Observed brown rust incidence

Fraction of aphid population killed due to control decision $d_{i}$

Fraction of brown rust population killed due to control decision $d_{i}$

Last day of decision period $i$

Number of Monte Carlo simulation runs

Sample size for estimating $I_{A}$

Sample size for estimating $I_{B}$

Number of decision periods

Duration of growth arresting effect on the aphid population following control decision $d_{i}$

Duration of growth arresting effect on the brown rust population following control decision $d_{i}$

Relative growth rate of the aphid population

Presence or absence of aphicidal effect

Relative growth rate of the brown rust population

Presence or absence of fungicidal effect

Maximum aphid damage

Maximum brown rust damage

Current day

Day on which control decision $d_{i}$ is made

Price of wheat

Attainable yield

Parameters of incidence-density relation, aphids

Parameters of incidence-density relation, brown rust

Parameters of damage per aphid-day crop development stage relation

Damage per sorus-day per unit attainable yield

Maximum brown rust damage per unit attainable yield

Parameter of crop development stage-temperature sum relation

Parameters of relative aphid growth ratecrop development stage relation
Unit

-

day

day

day '

day $^{-1}$

-

kg ha 1

kg ha '

$-$

Dff $\mathrm{kg}{ }^{\prime}$

kg ha ${ }^{\prime}$

$-,-$

$-,--$

kg kg '

(aphid day) '

$\mathrm{kg} \mathrm{kg}^{1}$

(sorus-day) $^{\prime}$

kg kg '

$\left({ }^{\circ} \mathrm{C} \text { day }\right)^{1}$

day ${ }^{\prime}$, day $^{-1},-$ 


Symbol
$\alpha_{X, f}$
$\varepsilon_{I_{A}}$
$\varepsilon_{I_{B}}$
$\varepsilon_{X_{X}}$
$\varepsilon_{P_{X}}$
$\varepsilon_{S_{A}^{\text {max }}}$
$\varepsilon_{W_{, A}}$
$\varepsilon_{W, B}$
$\varepsilon_{W, D}$
$\varepsilon_{W, W_{A}}$

\section{Definition}

Field specific version of parameter $\alpha_{8}$ Uncertainty in sample estimate $I_{A}$ Uncertainty in sample estimate $I_{B}$ Parameter uncertainty in $K_{1}\left(d_{i}\right)$ Parameter uncertainty in $P_{x}\left(d_{i}\right)$ Parameter uncertainty in $S_{A}^{\max }$ White noise in incidence-density relation aphids

White noise in incidence-density relation brown rust

White noise in crop development stagetemperature sum relation

White noise in relation between relative aphid growth rate-crop development stage

White noise in relative brown rust growth rate day 1 Parameter uncertainty in $\alpha_{i}$ Uncertainty in the parameters describing $r_{A}$ Residual variance of $i$ Variance of $i$ Covariance matrix labelled as $i$
Unit

day $^{-1}$

$-$

$-$

-

day

kg ha '

day ${ }^{\prime}$

variable day ', day ',variable variable variable

\section{REFERENCES}

Beck, M. B. (1987). Watcr quality modeling: a review of the analysis of uncertainty. Water Resonrces Research, 23, 1393-442.

Brown, J. S., Smith, E., Bcll, C. J. \& Price, T. V. (1986). Duration of control of stripe rust of wheat with foliar sprays. Australasian Plant Pathology, 15, 9-10.

Carlson, G. A. (1970). A decision theoretic approach to crop discase prediction and control. Americam. Journal of Agricultural Economics, 52, 216-22.

Carlson, G. A. \& Main, C. E. (1976). Economics of disease-loss management. Anmual Review of Phytopathology, 14, 381-403.

Carter, N., Dixon, A. F. G. \& Rabbinge, R. (1982). Cercal Aphid Populations: Biology, Simulation and Prediction. Pudoc, Wageningen, The Netherlands, 91 pp.

Chatterjec, S. \& Price, B. (1974). Regression Analysis By Example. John Wiley, New York, USA, 228 pp.

Chiarappa, L. (1974). Possibilities of supervised plant disease control in pest management systems. FAO Plamt Protection Bulletin, 22, 65-8.

Daamen, R. A. (1990). Surveys of cercal discases and pests. 1. Weather and winter wheat cropping during 1974-1986. Netherlands Joumal of Plant Pathologl, 96, 226-36.

Daamen, R. A. (1991). An advisory model for control of Puccinia recondita in winter wheat. Netherlands Joumal of Plant Patholog1, 97, 275-88. 
Dewar, A., Devonshire, A. L. \& french-Constant, R. H. (1988). The rise and rise of the resistant aphid. British Sugarbeet Review, 56, 40-3.

Drenth, H., Hoek, J., Daamen, R. A., Rossing, W. A. H., Stol, W. \& Wijnands, F. G. (1989). An evaluation of the crop-physiological and epidemiological information in EPIPRE. EPPO Bulletin, 19, 417-24.

Drenth, H. \& Stol, W. (1990). The EPIPRE Advisory Model (in Dutch). Lelystad, PAGV verslag nr. 97. Wageningen, The Netherlands, CABO verslag no. $115.130 \mathrm{pp}$.

Entwistle, J. C. \& Dixon, A. F. G. (1986). Short-term forecasting of peak population density of the grain aphid (Sitobion avena(') on wheat. Annals of Applied Biology, 109, 215-22.

Entwistle, J. C. \& Dixon, A. F. G. (1987). Short-term forccasting of wheat yield loss caused by the grain aphid (Sitobion avenae) in summer. Annals of Applied Biology, 111, 489-508.

Feller, W. (1971). An Introduction to Probahility. Theory and Its Applications, 2nd edn. John Wilcy, New York, USA.

Geng, S., Penning de Vries, F. W. T. \& Supit, I. (1985). Analysis and Simulation of Weather Variables: Temperature and Solar Radiation. Simulation Reports CABO-TT No. 5. Centre of Agrobiological Research and Department of Theoretical Production Ecology, Wageningen, The Netherlands.

Gold, H. J. (1989). Decision analytic modeling for plant disease control. In Plant Disease Epidemiology' $I I$, eds K. J. Leonard \& W. E. Fry. Macmilian Publishing Company, New York, USA, pp. 85-122.

Hertz, D. B. \& Thomas, H. (1983). Risk Analysis and its Applications. John Wiley, Chichester, UK, 326 pp.

Iman, R. L. \& Conover, W. J. (1980). Small sample sensitivity analysis techniques for computer model, with an application to risk assessment. Conmunications in Statistics, 9, 1749-842.

Iman, R. L. \& Conover, W. J. (1982). A distribution frec approach to inducing rank correlations among input variables. Communications in Statistics, Part $B$-Simulation and Computation, 11, 311-34.

IMSL (1987). Stat/library. FORTRAN subroutines for statistical analysis. Version 1.0. IMSL, Inc. $1231 \mathrm{pp}$.

Kremer, J. N. (1983). Ecological implications of parameter uncertainty in stochastic simulation. Ecological Modelling, 18, 187-207.

Mann, B. P. \& Wratten, S. D. (1989). A computer-based advisory for cereal aphid and oilseed rape-pest control. In Parasitis 88. Procecdings of a scientific congress, Barcelona, Spain, 25-28 October 1988, eds R. Cavalloro \& V. Delucchi. Boletin de Samidad Vegetal, Fuera de Scrie 17, 227-48.

McKay, M. D., Conover, W. J. \& Beckman, R. J. (1979). A comparison of three methods for selecting values of input variables in the analysis of output from a computer code. Technomerics, 21, 239-45.

Mumford, J. D. \& Norton, G. A. (1984). Economics of decision making in pest management. Annual Reriew of Entomology, 29, 157-74.

Nachman, G. (1981). A mathematical model of the fundamental relationship between density and spatial distribution of a population. Joumal of Animal Ecology, 50, 453-60.

Penning de Vries, F. W. T. (1977). Evaluation of models in agriculture and biology: conclusions of a workshop. Agricultural Systems, 2, 99-107. 
Poehling, H. M. (1987). Effects of reduced dose rates of pirimicarb and fenvalerate on aphids and beneficial arthropods in winter wheat. Bulletin SROP/WRPS Bulletin, X/1, 184-93.

Rabbinge, R. (1988). Implementation of integrated crop protection systems. Bulletin SROP/WPRS Bulletin. XI/2, 69-73.

Rabbinge, R., Ankersmil, G. W., Carter, N. \& Mantel, W. P. (1980). Epidemics and damage effects of cereal aphids in The Netherlands. Bulletin SROP/IVPRS Bulletin, III/4, 99-106.

Reinink, K. (1986). Experimental verification and development of EPIPRE, a supervised discase and pest management system for wheat. Netherlands Journal of Plant Pathology, 92, 3-14.

Rossing. W. A. H. (1991a). Simulation of damage in winter wheat caused by the grain aphid Sitohion arenae. 2. Construction and evaluation of a simulation model. Netherlands Joumal of Plant Pathology', 97, 25-54.

Rossing, W. A. H. (1991h). Simulation of damage in winter wheat caused by the grain aphid Sitobion arenae. 3. Calculation of damage at various attainable yicld levels. Netherlands Journal of Plant Pathology, 97, 87-103.

Rossing, W. A. H., Daamen, R. A. \& Hendrix, E. M. T. (1994a). A framework to support decisions on chemical pest control, applied to aphids and brown rust in winter wheat. Crop Protection (in press).

Rossing, W. A. H., Daamen, R. A. \& Jansen, M. J. W. (1994b). Uncertainty analysis applied to supervised control of aphids and brown rust in winter wheat. Part 2. Relative importance of different components of uncertainty. Agricultural Systems, 44, 449-60).

Sinn, H.-W. (1983). Economic Decisions Under Uncertainty. North-Holland Publishing Company, Amsterdam. The Netherlands, 359 pp.

Stein, M. (1987). Large sample properties of simulations using latin hypercube sampling. Te'dmometrics, 29, 143,51.

Tait, E. J. (1983). Pest control in brassica crops. In Advances in Applied Biology, cd. T. HI. Coaker, Vol. VIII, pp. 121 ..88.

Tait, E. J. (1987). Rationality in pesticide use and the role of forecasting. In Rational Pesticide Use, eds K. J. Brent \& R. K. Atkin. Cambridge University Press, UK, pp. 225-38.

Thornton, P. K.. Dent, J. B. \& Beck, A. C. (1984). An Information System for the Control of Brown Rust in Barley. Research Report 155. Agricultural Economics Unit, Lincoln College, Canterbury, New Zealand.

Van Kculen, H. \& Seligman, N. G. (1987). Simulation of Water Use, Nitrogen Nurrition and Growth of a Spring Wheat Crop. Simulation Monographs, Pudoc, Wageningen, The Netherlands, $310 \mathrm{pp}$.

Ward, S. A., Sunderland, K. D., Chambers, R. J. \& Dixon, A. F. G. (1986). The use of incidence counts for estimation of aphid populations. 3. Population development and the incidence-density relation. Netherlands Journal of Plant Pathology, 92, 175-83.

Zadoks, I. C. (1985). On the conceptual basis of crop loss assessment: the threshold theory. Ammual Revie'l of Phytopathology, 23, 455-73.

Zadoks, J. C. (1989). EPIPRE, a computer-based decision support system for pest and discase control in wheat: its development and implementation in Europe. In Plant Disease Epidemiology II, eds K. J. Leonard \& W. E. Fry. Macmillian Publishing Company, New York, USA, pp. 3-29. 
Zadoks, J. C., Chang, T. T. \& Konzak, C. F. (1974). A decimal code for the growth stages of cereals. Eucarpia Bulletin, 7, 42-52.

Zadoks, J. C., Rijsdijk, F. H. \& Rabbinge, R. (1984). EPIPRE: a systems approach to supervised control of pests and diseases of wheat in The Netherlands. In Pest and Pathogen Control. Strategic, Tactic and Policy Models, ed. G. R. Conway. John Wiley, Chichester, UK, pp. 344-51. 